\title{
La publicidad engañosa, una modalidad de estafa en las relaciones de consumo, de acuerdo al marco jurídico colombiano
}

\author{
Misleading advertising, a modality of fraud in consumer relations, \\ according to the colombian legal framework
}

\begin{abstract}
RESUMEN
El modelo que orienta la nueva legislación sobre los consumidores en Colombia parte de la vulneración de los derechos que se tienen para con estos, en especial lo referente a la publicidad engañosa que cada día va incrementando debido a la necesidad que se tiene de adquirir un producto, bien o servicio, ofrecido por un determinado grupo de personas llamadas proveedores o productores. El presente trabajo destaca de manera sucinta cómo la publicidad engañosa pasa a ser considerada estafa en las relaciones de consumo, utilizando para ello los criterios normativos colombianos.

No obstante los resultados obtenidos con relación a las diferentes lecturas realizadas a lo largo de esta investigación, podemos concluir que la publicidad engañosa sí puede conllevar al delito de estafa, en algunos aspectos que en el desarrollo de este trabajo se detallan. Frente a estos resultados, se hace necesario preguntarnos ¿Qué políticas de prevención ha utilizado el Estado con respecto a la publicidad engañosa?
\end{abstract}

\section{PALABRAS CLAVE}

Publicidad engañosa, Estafa, Relación de consumo.

\section{ABSTRACT}

The model that guides the new consumer legislation in Colombia of the violation of the rights that are held for these, especially with regard to misleading advertising that every day is increasing due to the need we have of acquired product, good or service offered by a particular group of people called suppliers or producers. This paper highlights succinctly as misleading advertising to be considered fraud in consumer relations, using Colombian regulatory criteria.

However the results obtained in relation to the different readings perform throughout this research reflects us that if misleading advertising can lead to swindle, but in some aspects in the development of this work will come to detail. Given these results, it is necessary to ask what prevention policies has used the State concerning misleading advertising?

\section{KEYWORDS}

Misleading advertising, Fraud, Consumer relationship.

\section{OSCAR IVÁN ACOSTA LOBO}

Egresado de la Facultad de Derecho y Ciencias Políticas de la Corporación Universitaria del Caribe (CECAR). Miembro del Semillero de Derecho Privado Derechos de Consumo de CECAR. oscar.acosta@cecar.edu.co

LICETH ANDREA SALAZAR ÁLVAREZ

Egresado de la Facultad de Derecho y Ciencias Políticas de la Corporación Universitaria del Caribe (CECAR). Miembro del Semillero de Derecho Privado Derechos de Consumo de CECAR. liceth.salazar@cecar.edu.co

BERÓNICA NARVÁEZ MERCADO

Directora del Semillero de Derecho Privado Derechos de Consumo de la Corporación Universitaria del Caribe (CECAR). beronica.narvaez@cecar.edu.co 


\section{INTRODUCCIÓN}

Las economías de mercado imperantes en nuestro país se han caracterizado por generar sociedades de consumo, conformadas por productores, proveedores y el destinatario final que es el consumidor, que en esta relación actúa como sujeto pasivo que requiere adquirir bienes o servicios para satisfacer una serie de necesidades. En este sentido, los productores o proveedores pueden ejercer sobre el consumidor un cierto grado de manipulación en sus decisiones al publicitar de manera inadecuada los productos que ofrecen al mercado con el fin de incrementar su propia demanda, pues de esta forma hacen que las personas aumenten su deseo de obtener determinado bien o servicio por ellos ofrecidos, sin importar la forma en la que se presente o se dé a conocer el producto, lo que implica una desnaturalización de la publicidad que debería estar orientada a informar objetivamente a quien la adquiere y no a persuadir en su decisión. Para evitar este tipo de acontecimientos, en el año 2011, fue creado el Estatuto del Consumido o la Ley 1480 de 2011, la cual entró en vigencia el 12 de abril de 2012, con el fin de regular los temas referentes a la protección que deben tener los consumidores, dándole cabal cumplimiento a lo establecido en la Constitución Política de 1991 en su artículo 78 que dispone los preceptos generales para la protección al consumidor, los cuales son de carácter proteccionista y preferenciales ante cualquier norma general.

Este Estatuto también hace referencia en e artículo 5 numeral 13, a la publicidad engañosa, definiéndola como aquella cuyo mensaje no corresponde a la realidad o sea insuficiente, de manera que induzca o pueda inducir a error, engaño o confusión, con el fin de evitar que los consumidores se puedan ver afectados con este tipo de publicaciones. En tal sentido los productores o proveedores están en la obligación de ofrecer una información veraz y suficiente sobre el producto que expone a la venta, a garantizar que e consumidor reciba el producto que se le est ofreciendo en óptimas calidades y que este sea idóneo, dado que todos los elementos contribuyen a una buena relación de consumo y al respeto de los consumidores y la ley. Por su parte, es bueno saber cuándo estamos frente a una estafa. Para ello, el marco jurídico colombiano nos remite a la Ley 599 de 2000 o Código Penal colombiano, que en el artículo 246 establece esta figura jurídica como un delito y que literalmente dice: "e que obtenga provecho ilííito para sí o para un tercero, con perjuicio ajeno, induciendo manteniendo a otro en error por medio de artificios o engaños" (Artículo 246).

Ahora bien, teniendo claras las dos figuras jurídicas y la definición de cada una de ellas, hemos decidido guiar el sentido de nuestra investigación, en el marco de la publicidad engañosa, un modalidad de estafa en las relaciones de consumo, en el marco jurídico colombiano, teniendo como base la normatividad de la Ley 1480 de 2011 y la Ley 599 de 2000, con el propósito de determinar si la publicidad engañosa, es una modalidad de estafa en las relaciones de consumo, según el marco jurídico colombiano. Para ello debemos identificar cuándo estamos frente ana estafa y cuándo estamos frente a una publicidad engañosa, basándonos en los diferentes análisis jurisprudenciales.

Esperamos que esta investigación sea relevante, pertinente y útil para todos aquellos consumidores que se han visto afectados por esta serie de situaciones $y$ con el fin de prevenir futuras y posibles afectaciones, puesto que si no se resuelve el problema jurídico que hemos planteado, se seguiría en un vacío normativo, el cual permite que reine la incertidumbre jurídica, lo cual afectará en 列 ción y la ley de este país.

También es importante resaltar que con este tipo de investigaciones contribuimos a dejar un lado el desconocimiento de la Norma y aprendemos a interpretarla desde diferentes ámbitos, dado que el Derecho nos permite hace una buena hermenéutica sobre los artículos contenidos en cada una de las normas que conforman el ordenamiento jurídico colombiano.

\section{METODOLOGÍA}

sta investigación se caracteriza por ser un studio cualitativo con un nivel hermenéutico, pues se buscó determinar, interpreta y comprender si la publicidad engañosa, es una modalidad de estafa en las relaciones de consumo, de acuerdo al marco jurídico colombiano. La fuente objeto de análisis fue la Ley 1480 de 2011 o Estatuto del Consumidor en Colombia, el cual consagra la publicidad engañosa y la Ley 599 de 2000 que hace referencia al delito de estafa.

Para desarrollar los objetivos específicos de la investigación, se llevaron a cabo las siguientes etapas:

ETAPA 1: Se hizo un rastreo bibliográfico del tema mediante la consulta de varias bases de datos jurídicas (Dialnet, Vlex, Scielo, ScienceDirect, etc.), en la que se usó como criterio de selección de información, los descriptores restrictivos: "estafa, publicidad engañosa, relaciones de consumo". Seleccionado el material bibliográfico, se procedió a su lectura, y con base en ellas se extrajo la información relevante sobre las semejanzas y diferencias entre la publicidad engañosa y la estafa, las cuales fueron objeto de análisis e interpretación posterior, a través del método de análisis comparativo y diferencial.

ETAPA 2: Se elaboró una matriz donde se relacionaron, en columnas separadas, los requisitos exigidos por el Código Penal para determinar el delito de estafa. Luego, un análisis con lo establecido en el artículo 5 numeral 13 del Estatuto del Consumidor (Ley 1480 de 2011), para poder determinar el grado de inferencia de las dos figuras jurídicas. 
I. RELACIONES DE CONSUMO

La Ley 1480 de 2011 o Estatuto del Consumidor se ha encargado de regular los asuntos derivados de las relaciones de consumo que se generan a diario en la cadena de producción, es decir, entre productores, proveedores y el consumidor, pero no establece una definición como tal para las relaciones de consumo, por lo que para poder entender a qué se refiere nos remitimos a definiciones utilizadas en otros países como Uruguay, que regula las relaciones de consumo en la Ley 17.250 de 2000, art. 4 como: "el vínculo que se establece entre el proveedor que, a título oneroso, provee un producto o presta un servicio y quien lo adquiere y utiliza como destinatario final. La provisión de productos y la prestación de servicios que se efectúan a título gratuito, cuando ellas se realizan en función de una eventual relación de consumo, se equiparan a las relaciones de consumo". Por su parte Paraguay establece en la Ley 1.334 de 1998, art. 5, que la "Relación de consumo es la relación jurídica que se establece entre quien, a título oneroso, provee un producto o presta un servicio y quien lo adquiere o utiliza como destinatario final".

En tal sentido podemos utilizar estas definiciones que dan otros países y amoldarlas de acuerdo a lo que nuestra normatividad quiere dar a entender. En este aspecto diríamos que la relación de consumo no es más que el vínculo existente entre el productor, proveedor y el consumidor, siendo el primero quien ofrece un producto, bien o servicio y el segundo quien lo adquiere. En este orden de ideas solo habrá relación de consumo cuando el consumidor haya adquirido el bien ofrecido por el proveedor o producto y haya pagado un precio.

Teniendo claro este nuevo concepto, es más fácil determinar cuándo existe relación de consumo y cuándo no, pues esto se convierte en un factor determinante a la hora de determinar quién es considerado consumidor.

\section{LA PUBLICIDAD ENGAÑOSA}

En Colombia, la publicidad engañosa viene siendo regulada por la Ley 1480 de 201 en su artículo 5 numeral 13 como "aquell cuyo mensaje no corresponda a la realidad o es insuficiente, de manera que induzca pueda inducir a error, engaño o confusión Pero, ¿cómo se configura esta sanción administrativa? La Superintendencia de Industria y Comercio nos enfatiza que se está frente a esta figura cuando se presenten las siguientes condiciones:

1. Se omite información necesaria para la adecuada comprensión de la propaganda comercial.

2. Cuando la información indispensable para el adecuado manejo, mantenimiento, forma de empleo, uso del bien $y / 0$ servicio así como precauciones sobre posibles riesgos, no esté en idioma castellano.

3. Se establecen mecanismos para trasladar al consumidor los costos del incentivo de manera que este no pueda adver- tirlo fácilmente, como cuando se disminuye la calidad o cantidad del producto o servicio o se incrementa su precio, entre otros.

4. La información sobre restricciones, limitaciones, excepciones y condiciones adicionales para la adquisición del producto o servicio, no se incluye en la propaganda comercial y no tiene similar notoriedad al ofrecimiento del producto o servicio que se anuncia.

5. Se ofrecen productos o incentivos con deficiencias o imperfectos, usados, manufacturados, remodelados o reconstruidos, próximos a vencerse y de colecciones o modelos anteriores sin indicar tales circunstancias de manera clara y precis en la propaganda comercial.

Se ofrecen de manera gratuita productos, servicios o incentivos cuando la entrega de los mismos está supeditada al cumplimiento de alguna condición por parte del consumidor que no se indica en la propaganda comercial.

Con base en estos criterios de configuración y teniendo en cuenta su definición es importante resaltar que no solo las publicaciones que se hacen por Internet, por televisión o cualquier medio masivo de comunicación configuran publicidad engañosa, sino que también existen criterios de divulgación diferentes a los ya mencionados que la pueden generar.

Un ejemplo claro para este tipo de situaciones serían los medicamentos que traen del extranjero que en su empaque o en sus contraindicaciones no vienen traducidas en idioma castellano o español, para que el consumidor pueda utilizar adecuadamente el medicamento sin que les cause algún tipo de riesgo a su salud física o emocional. En este caso es claro que existe un criterio de configuración de la publicidad engañosa, para o cual es necesario que el producto que ingrese desde el extranjero venga traducido al idioma castellano o español para que pueda ser comercializado en nuestro país, sin causar afectaciones a los consumidores.

Cabe resaltar que no es necesario adquirir el producto para que se configure la publicidad engañosa, solo con la simple difusión o puesta en conocimiento al público hace que se configure, por lo tanto todas las personas que de una u otra manera vean o se sientan fectados con este tipo de publicaciones que no están de acuerdo con lo que el producto comercializado promete, pueden ponerlo en conocimiento a la Superintendencia de Industria y Comercio para evitar posibles afectaciones.

III. PUBLICIDAD ENGAÑOSA EN LAS RELACIONES DE CONSUMO

Teniendo claro estos dos aspectos -la publicidad engañosa y la relación de consumo-es importante decir que la simple publicidad engañosa que se haga por cualquier medio no hace suponer que se está en una relación de consumo, porque no ha adquirido ni pa- 
por lo tanto tampoco puede ser considerado consumidor, aunque dicha publicación tenga información imparcial, incompleta o mentirosa y pueda llegar a afectar al consumidor.

Por su parte, una vez el consumidor haya adquirido el producto, bien o servicio ofrecido de forma engañosa, es deber del productor o proveedor responder ante las posibles afectaciones que se llegaren a presentar a causa de la omisión de información o de las posibles afectaciones a la salud o la vida del consumidor, en este sentido tenemos que tener claro que es deber del consumidor activar las rutas de protección que ha creado la Superintendencia para hacer efectivo su derecho como consumidor, pues en este caso resultan en juego diferentes afectaciones que deben ser resarcidas si se hacen a tiempo. Pero, ¿cómo se hace efectivo? Pues bien, una vez activada la ruta que consiste en la reclamación directa ante el productor o proveedor, este debe reparar el daño causado por su omisión de información o por engañar o inducir en error al comprador. Si esto no sucede, el consumidor tiene la facultad de interponer una acción de protección al consumidor ante la Superintendencia de Industria y Comercio (SIC) que no es más que una demanda para que la entidad o empresa responda por los daños causados, así como también puede hacerlo ante un juez de la República, cuando resulte lesionado en gran medida su patrimonio o sea necesario una indemnización por los perjuicios causados. En tal sentido, es deber de la Superintendencia vigilar que este tipo de situaciones no se sigan presentando ha- ciendo un respectivo control a las empresas que comercializan, distribuyen o crean bienes, productos o servicios.

IV. LA ESTAFA Y LA PUBLICIDAD ENGAÑOSA VISTAS DESDE OTRO ENFOQUE

A través de los tiempos mucho se ha hablado de la estafa como un delito que atenta contra el patrimonio económico de las personas. En este sentido podemos decir que esta figur no es más que una conducta engañosa que permite inducir a error a una o varias personas con el fin de sacar un provecho económico ya sea para quien realiza la acción o para otra persona.

Ahora bien, para poder entender esta figura desde otra órbita diferente a la penal es necesario analizar cada uno de los elementos penales que la conforman relacionándolos o trayéndolos a la esfera de la publicidad engañosa como sanción administrativa. En ese sentido tenemos:

SUJETOS: Tanto el activo como el pasivo son indeterminados, siendo este último, es decir, el pasivo, el que tiene un patrimonio económico del cual el activo quiere sacar un provecho. Si miramos estos sujetos en las relaciones de consumo, esta no varía, pues siguen siendo los mismos sujetos indeterminados que para tema a tratar, sería el sujeto activo el que publica o da a conocer el producto bien o servicio, y el sujeto pasivo el que adquiere el producto, es decir, el consumidor.
MODo: La principal herramienta de la estafa es Inducción a error o mantener a otro en error mediante artificios o engaños. En este aspecto la publicidad engañosa tiene el mismo modo de operar y es manteniendo o induciendo a engaño o error al consumidor, pues en ese sentido se podría decir que $s$ existe una relación concursal entre estas dos figuras jurídicas.

BIEN JURídICO TUTELADO: El bien jurídico que se protege es el patrimonio económico de las personas, pero si damos un vistazo al ámbito administrativo ejercido por la Ley 1480 de 2011, lo que se busca es proteger el paimonio de los consumidores que pueden o tienen una relación de consumo.

BENEFICIO: Este delito tiene como finalidad obtener un beneficio económico, aunque con la sola intención de tenerlo sin conseguirlo también puede ser configurado, puesto que admite tentativa. Para tales efectos sería lógico pensar que la publicidad engañosa tiene el mismo modus operandi, pues mbién busca un provecho económico, aun con la sola publicación estaríamos frente una tentativa como se miraría si este estuviera tipificado como delito.

Examinados cada uno de estos elementos y En este sentido, la Corte Suprema de Justicia su relación con la publicidad engañosa pode- en la Sentencia del 23 de junio de 1958, mamos determinar que la publicidad engañosa nifestó que "en la celebración de contratos puede trascender a la esfera de la estafa, de naturaleza civil se puede incurrir en el desiempre y cuando el consumidor actúe con lito de estafa. En este sentido se viene prohila determinada prudencia para no caer en jado el criterio según el cual en esa clase de error o si lo está, poder salir de él. De lo con- negocios jurídicos la mentira o el silencio de 
los contratantes pasa al campo penal cuando de en algunos casos corroborar la informarecaen sobre elementos fundamentales del ción que le ofrecen del producto o proveeconvenio" y que:

El medio engañoso debe tener idoneidad

para inducir en error a la víctima. La estafa

es un delito de inteligencia, que requiere

el despliegue de actos hábilmente pre-

parados y bien concebidos para revestir

capacidad de inducir en error a la víctima.

Bajo tal perspectiva, entonces, tenemos que en este caso sí existió falta en los elementos del contrato los cuales son indispensables en la relación de consumo que para nuestro entender puede considerarse también como un contrato o convenio. En tal sentido, si el producto adquirido no cumple con las cualidades y no es idóneo para lo que se adquirió se podría decir que estamos en presencia de una estafa, al tener claro que María obró de una forma ingenua, torpe y negligente al no saber o conocer si el producto que le están ofreciendo sí cumplía con las condiciones anunciadas y que además era idóneo para la pérdida de peso. En consecuencia podemos decir que cuando el consumidor haya entrado en una relación de consumo al adquirir e producto a través de una publicidad engañosa y que dicha relación haya causado daño a su patrimonio, se estaría frente a la figura jurídica del delito de estafa.

Ahora bien, cabe aclarar que no siempre que se está en una relación de consumo producto de una publicidad engañosa. Estamos frente a una estafa y es porque el consumidor pue- ción que le ofrecen del producto o proveesería cuando se quiere adquirir un bien, objeto de registro; verificando la información podemos determinar si lo que nos ofrecen concuerda con la realidad y de este modo evitar ser estafados.

Una vez desarrollado lo que es el delito de la estafa y la publicidad engañosa, podemos de una manera más clara entender en qué momento nos encontramos afectados por este ya que si bien es cierto que guarda mucha similitud entre la definición de la estafa y la definición de lo que es la publicidad engañosa, materialmente no son iguales. Lo que $s$ podríamos afirmar es que una puede ser un vehículo o lo que conlleva a la otra, es de cir, que la publicidad engañosa es el vehículo o el medio para llegar a la estafa, ya que es mediante esta que se logra inducir o llamar la atención de los consumidores para que tengan una relación de consumo, pero utiIzando algunos artificios o engaños que los induzcan al error, con el fin de convencerlos de que los que se está ofreciendo es lo que finalmente quiere y desea adquirir, y resulta siendo todo lo contrario.

En consecuencia, cuando el consumidor no haya adquirido el producto, bien o servicio, a única herramienta que tiene es presentar una denuncia ante la Superintendencia de Industria y Comercio, por publicidad engañosa que esté realizando algún productor o determinado momento. Un ejemplo de esto proveedor, con el fin de evitar posibles afectaciones a los consumidores. Pero cuando haya adquirido el producto, bien o servicio y este no cumpla con las condiciones estipuladas por el productor o proveedor y eso genere una afectación a su patrimonio, entonces estaríamos frente al delito de estafa, dando lugar a que el consumidor pueda impetrar una demanda penal.

\section{CONCLUSIÓN}

Con el análisis realizado a las normas antes mencionadas y luego de una ardua labor investigativa, de lectura, podemos concluir camino que puede conllevar a configurar e delito de estafa. Si bien sus definiciones son parecidas, su criterio de aplicabilidad son diferentes, pues mientras una es una sanción administrativa, la otra es considerada como un delito, que para su configuración requiere de elementos necesarios e indispensables para considerar su ocurrencia.

Por su parte se puede decir que en una relación de consumo que venga viciada de publicidad engañosa lo más probable es que e presente una estafa, pero solo cuando el consumidor haya actuado de cierta forma que le sea imposible corroborar la información de lo que le están ofreciendo, de lo contrario solo se estaría en presencia de una publicidad engañosa que es sancionada por SIC, con criterios establecidos en sus resoluciones.

Cabe resaltar que la simple publicación no tafa_17.htm consumo. tos. que la publicidad engañosa es el medio o el

genera relación de consumo porque cuando no se ha adquirido el bien, producto o servicio ofrecido, solo se está en una relación de

Jurídicamente se ha avanzado en este tema, por cuanto la Superintendencia de Industria y Comercio está haciendo una ardua labor al prevenir la publicidad engañosa, así mismo los consumidores cada día son más responsables al momento de adquirir sus produc-

Como políticas de prevención para los consumidores, recomendamos que cada vez que se pretenda adquirir un bien, producto $o$ servicio, verifiquemos que sí cumpla con las condiciones, calidades o cualidades publicitadas; de esta manera estaríamos actuando de forma responsable, evitando posibles afectaciones a nuestro patrimonio, y si por su parte ya han sido objeto de publicidad engañosa poner en conocimiento de la SIC, para evitar que se sigan presentado.

\section{REFERENCIAS}

Corte Suprema de Justicia en su Sala de Casación Penal. Casación N 28693 del 10 de junio de 2008. Magistrada ponente: María del Rosario González de Lemos.

llido, A. A. (17 de abril de 2013). Blog de Derecho Penal Especial Uno. Universidad Cooperativa de Colombia; Neiva, Huila: Disponible en: http://tituloviipenalespecialuno.

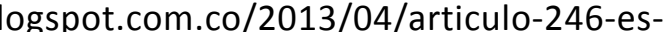

- REVISTA VIS IURIS I No. 4, Vol. 2171 - 80 I Juilo-Diciembre, 2015 I Universidad Sergio Arboledal I Escuela de Derecho I Seccional Santa Marta, Sede Centro 
Ley 820 (10 de julio de 2003). Por medio del cual se expide el régimen de arrendamiento de vivienda urbana y se dictan otras disposiciones. DO: 45.244 , Congreso de Colombia, Colombia.

Ley 1480 (12 de octubre de 2011). Por medio de la cual se expide el Estatuto del Consumidor y se dictan otras disposiciones. Diario Oficial No. 48.220, Congreso de Colombia, Colombia.

Ley 599 (24 julio de 2000). Por la cual se expide el Código Penal. DO: 44.097, Congreso de Colombia, Colombia.
Ley 17.250 (11 de agosto de 2000). Ley de Relaciones de consumo. Defensa del consumidor. DO: 44.097, Congreso de Uruguay, Uruguay.

Ley 1334 (11 de agosto de 2000). De defensa del consumidor y del usuario. DO: 44.097, Congreso de Paraguay, Paraguay. 